\title{
The dynamics of issue competence and vote for parties in and out of power: An analysis of valence in Britain, 1979-1997
}

\author{
JANE GREEN \& WILL JENNINGS \\ School of Social Sciences, University of Manchester, UK
}

\begin{abstract}
This article develops the reward-punishment issue model of voting using a newly collated aggregate measure of issue competence in Britain between 1971 and 1997, revealing systematic differences between governing and opposition parties in the way citizens' evaluations of party competence are related to vote intention. Using monthly Gallup 'best party to handle the most important problem' and vote intention data, time series Grangercausation tests give support to a classic issue reward-punishment model for incumbents. However, for opposition parties this reward-punishment model does not hold: macro-issue competence evaluations are Granger-caused by changes in vote choice or governing party competence. An explanation is offered based upon the differentiating role of policy performance and informational asymmetries, and the implications are considered for comparative studies of voting, public opinion and for political party competition.
\end{abstract}

Keywords: valence; competence; incumbents; oppositions; vote choice

Few scholars would deny that political leaders are evaluated on their performance or that this has important implications for voting, as well as for the quality of representation that citizens are given. Competent managers of public services and the economy are rewarded, whereas serious policy mismanagement rarely goes unpunished. Political candidates and parties seek to emphasise any positive record of performance, trust or positive policy issue handling. Incumbent parties can benefit in this respect from the time, attention and scope with which they can demonstrate competence and trustworthiness on the important issues of the day. Opposition parties, on the other hand, cannot demonstrate managerial capabilities in the same time period via performance in office. Voters therefore have less information about how an opposition candidate would manage key policies and services, and rely instead upon retrospective or hypothetical evaluations of the opposition (Fiorina 1977, 1981). Competence and performance information differences should be particularly important if policy handling evaluations are at the forefront of vote choices, in a context of 'valence politics' (Stokes 1963; Clarke et al. 2004, 2009; Green 2007; Green \& Hobolt 2008), and also at the forefront of party strategies, whereby government and opposition parties seek to emphasise issues on 
which they have a stronger reputation for competence (see Budge \& Farlie 1983; Budge 1987; Petrocik 1996; Petrocik et al. 2003; Riker 1993).

In important work, Butt (2006) highlights systematic government and opposition differences with respect to economic voting. Building on this research, we ask: does 'valence politics' apply to governing and opposition parties alike with respect to a diverse range of policy issues and should we apply the reward-punishment model of voting to policy issues for parties in and out of power? These questions are important not only for the political behaviourist interested in better understanding voting behaviour, public opinion and political competition, but also for parties and citizens concerned with the alternation of government from one candidate to another.

This article presents analyses of macro-level measures of issue competence ratings of political parties in government and in opposition, and their relationship to vote intention. The cases are taken from Great Britain over a period of 26 years. The analyses are based on a newly compiled dataset of issue competence for three parties over six electoral cycles, encompassing two alternations of British Labour and Conservative Governments. The British case provides the most extended range of available, continuous data points, uniquely offering an opportunity to study monthly variation and also to test the dynamics between issue competence, economic expectations, government and leader approval, and important events. The British political system has clear governing and opposition party status with a centralised system of power (Lijphart 1984), which makes this case ideal to test for clear dynamics attributable to opposition and governing parties. Until now, longitudinal measures of issue competence have not been analysed in aggregate vote intention models, and so the analyses illuminate new questions regarding the dynamics of issue valence for political choice.

The findings reveal that voters evaluate opposition parties according to their relative assessment of the performance of the government and using their pre-existing vote support - with important implications for our understanding of the campaigning incentives of opposition parties. The findings also provide caution to scholars who may relate reward-punishment models of competence to all parties alike, whether in office or out of office. This can be useful - and important - for the application of performance models of party choice in different contexts, and for an understanding of public opinion dynamics and vote choices for different candidates over time.

The article extends and builds upon work analysing these questions related to the economy in the United Kingdom (Butt 2006) and provides the first analysis examining this question over a long period of time - with alternations of governing party status. The findings point to a substantively important effect of issue competence ratings and their interplay with vote intention, 
representing, to the best of our knowledge, the first longitudinal study of issue valence across diverse policy areas, and the first analysis of the statistical inter-relationships between long-term issue valence judgements and vote intention. This extends work revealing the importance of valence issues in recent British elections (Clarke et al.2004,2009), and offer scholars a means to analyse and understand the significance of issue valence in a dynamic context of government and opposition party status. Taking incumbent and challenger status into account may provide important new insights into party strategies and vote choices in ways that can be central to our understanding of political behaviour.

\section{Performance models of political choice}

Despite a growing interest in issue competence-based explanations of political choice and competition (see Clarke et al. 2004, 2009; Bellucci 2006; GreenPedersen 2007; Belangér \& Meguid 2008; Green \& Hobolt 2008), relatively little scholarly attention has been paid to the formation of party and candidate reputations for competent issue handling, or to the possibility of bi-directional causal relationships between party choice and issue competence.

The effects of issue competence have been theorised at the elite level, relating to candidate incentives to emphasise different issues in campaigns. The issue ownership theory of Petrocik (1996; Petrocik et al. 2003), the saliency theory of Budge and Farlie (1983; Budge 1987) and the dominance/dispersion theory of Riker (1993) argue that candidates gain votes by shifting voters' attention onto relative policy performance strengths - they give selective emphasis to issues they believe will benefit them. Parties and candidates should prime voters to cast their votes on the basis of their most advantageous issues and diminish the salience of issues on which an opponent holds an advantage (Iyengar \& Kinder 1987; Jacobs \& Shapiro 1994; Enelow \& Hinich 1981; Vavreck 2009).

The main voting assumptions to date could be viewed as similar to Fiorina's $(1977,1981)$ 'reward-punishment' model of voting. Voters reward the incumbent if policy performance has been good and punish the incumbent if it has performed badly, and are more likely to blame an incumbent for its mistakes than reward it for its successes (Anderson 1995). Just as different issues can be thought of as utilities, impacting upon vote choices similarly to economic performance (Van der Eijk et al. 2006), so issue competence can be viewed as in an issue reward-punishment dynamic with voting, most relevant to 'valence issues' (Stokes 1963), wherein voters choose between parties based upon competence because they perceive minimal policy differences on the issue (an 
argument developed and tested in the British context by Green (2007), Green \& Hobolt (2008), and by Clarke et al. (2004, 2009)). Valence issues and policy judgements on competence, and their effects upon vote choice, have been related to governing parties and to oppositions (see Clarke et al. 2004, 2009). However, it is plausible to suggest that issue or policy competence may be more strongly related to vote decisions for the incumbent.

Butt (2006) revealed an important asymmetric relationship between economic voting for governing and opposition parties in Britain: voters are more likely to reward or punish the incumbent party on the economy since they have reliable information about performance, but are less likely to relate economic evaluations to voting for the opposition. Fiorina (1977: 608) theorised such an asymmetry between information about the incumbent and opposition, stating: 'In making his voting decisions the citizen looks at the incumbent's performance, the alternative platforms of the incumbent and challenger and (perhaps) imagines a hypothetical past performance term for the previous challenger.' It is naturally harder for a voter to evaluate the hypothetical performance of a challenger than it is the actual performance of an incumbent. Not only is performance in office a palpable cue, but the incumbent is the focus of greater scrutiny, and voters experience the policy outcomes delivered in office.

The incumbent party can be stringently evaluated on competence, suffering from 'the costs of governing' (Miller \& Wattenberg 1985). Sniderman et al. (1991: 166) argue:

The incumbent has a prominence the challenger finds hard to match. He has been in the most visible public office for four years. The media have focused on the incumbent for his term; and focus more on him during the campaign in his double role as both president and candidate... By contrast, the public knows less about the challenger so the challenger lags behind public awareness.

Voters' ratings of opposition competence may not be associated with vote choices for these parties. Powell and Whitten's (1993) 'clarity of responsibility' hypothesis proposes that voters do not attribute responsibility for the economy when they have less reliable information about policy responsibility. This theory, applied to coalition governments, has implications for opposition parties. In the absence of information, voters may not relate performance effects to vote choices for opposition parties.

However, if voters do form competence evaluations of oppositions, and if these are associated with these parties' support, how might voters form their evaluations of opposition parties' likely competence? We suggest three potential sources of information. Voters may recall the performance of the 
opposition party when that party was last in power, and store this competence information to form evaluations of likely managerial competence in future. We might expect there to be 'memory' in public opinion ratings of opposition parties from previous periods in office, and for voters to form reliable competence judgements based upon the party's general reputation for good management. In this case, the reward-punishment model of issue voting would apply to parties in and out of power.

Another possible route to formulating competence ratings would be to use other existing information. Previous research has shown that voters with lower political knowledge or information are more likely to employ existing heuristics in place of concrete economic evaluations (see Downs 1957; Lodge \& Hamill, 1986; Conover et al.1986; Sniderman et al.1991). Butt (2006) proposes that voters may rely on leader evaluations or predispositions towards parties when they evaluate parties in opposition. Evans and Andersen (2006) demonstrate the degree to which voters formulate economic evaluations of parties from the partisan conditioning of perceptions of economic ratings, occurring particularly in contexts of low information. Other studies have also argued that perceptions of the economy are strongly conditioned by candidate or party preference and vote choice (see Wilcox \& Wlezien 1996; Wlezien et al. 1997; Anderson et al. 2004). A longstanding literature on bias, conditioning and assimilation explains these effects as being due to strong affiliations generating biases in evaluations of party or candidate performance. ${ }^{1}$ For parties in opposition, therefore, voters may rely on their prior support to formulate ratings of issue competence.

One further means through which voters may judge the opposition is simply in response to their ratings of the incumbent. It is obvious, but important, to note that voters necessarily rate parties in comparison with one another. The 'best' party on the economy will not remain the incumbent if voters believe the incumbent has managed the economy extremely badly. Petrocik (1996) argues that issue 'ownership' (a positive association between a party and an issue) can change from incumbent to challenger when the incumbent suffers a reputational crisis due to significant policy events. Ideologically, if a right-of-centre party has presided over a significant policy failing, voters may naturally turn to a left-of-centre party to handle the issue differently. If a party has been in opposition for a prolonged period, and the most obvious performance information relates to the incumbent, then voters may simply decide that anything is better. When an opposition claims it is 'time for change', voters may agree, and vote accordingly, simply by virtue of their negative performance evaluations of the incumbent. Hence, issue competence may be transferred from one party to another, when one (the incumbent) is perceived to perform very badly, or very well, on a given policy domain. 


\section{Expectations of competence effects and vote choices}

The above discussions offer a mixed set of expectations regarding the nature of issue competence relationships to vote choice. On the one hand, we would expect there to be a simple reward-punishment effect of issue competence ratings on party choice, for all parties, irrespective of whether a party is in or out of power. Equally, there is an expectation that any such rewardpunishment effect would be direct and robust when voters judge the party in power on its performance. For these parties, or candidates, the rewardpunishment model of issue voting is straightforward. It can be summarised in the following hypothesis.

H1: Changes in relative issue competence ratings will result in changes in vote intentions.

For opposition parties, we must also allow the possibility that this hypothesis will not hold:

H2: Changes in relative issue competence ratings will not result in changes in vote intention for parties in opposition.

Additionally, we can allow for opposition issue competence ratings to exist in a more complex relationship with party support. According to the available theoretical priors, a number of additional possibilities arise. The first is that voters' partisan predispositions drive the ratings of opposition parties and candidates. In the absence of reliable information about performance, a voter's prior vote intention will provide a more reliable heuristic. In a directional sense, the reward-punishment hypothesis (H1) would then be reversed. Prior vote choice would be a more reliable predictor of issue competence ratings for parties or candidates in opposition. ${ }^{2}$ This can be summarised as the 'opposition party hypothesis':

H3: Changes in vote intention will result in changes in the issue competence ratings of opposition parties.

Finally, we expect that in the absence of reliable opposition performance information, voters may formulate their opposition party issue ratings with regard to their evaluations of the incumbent. If the incumbent performs badly, the relative performance of the opposition will be higher, and voters may use this reliable information about the incumbent to form a rational but relative 
judgement about the challenger. We can therefore propose the 'incumbentopposition hypothesis':

H4: Changes in incumbent issue competence ratings will result in changes in opposition issue competence ratings.

In the analyses below, the hypotheses are tested using the method of Granger-causation. Tests for Granger-causation determine whether prior values of issue competence, or vote choice, improve prediction of current values of the dependent variable, controlling for prior values of the dependent variable (the method is elaborated below). This relates to the temporal ordering of variables, even if these move together over time, to determine whether issue competence tends to lead vote intention or whether vote intention tends to lead issue competence. The hypotheses are therefore tested with regard to the unique statistical information added to forecasting of each variable in the context of opposition and incumbent party status.

\section{Macro-level measures and analysis}

In many classic vote studies, evaluations of candidates and leaders are examined at the individual or micro-level. The theoretical discussion has also suggested that there may be something important in the way individuals evaluate incumbents and oppositions. However, it is not possible to conceptualise or test variation at the level of the individual in the degree to which a party or candidate is an incumbent or an opposition, and party and opposition effects are not distinguishable at one point in time. Micro-level indicators of issue competence are not available in multiple elections. While conclusions must therefore be drawn at the aggregate level, the insights gained into long-term trends in competence evaluations and vote intentions are very useful.

A macro-level measure of issue competence was constructed using monthly observations over a 26-year period - the longest available period with these data. The measure provides an approximated summary measure within the electorate (measured as the aggregate of individual survey respondents) of the overall evaluation of a party as 'the best party to handle the most important/ urgent problem'. This is similar, if not identical, to Petrocik's (1996) measure of issue ownership: 'a reputation for greater competence on handling the issues about which the voter is concerned'. Simply, the measure represents a level of general perceived competence to handle the policy challenges of the day. ${ }^{3}$ The question does not generate a perfect mirror image of government and opposition ratings; it offers a choice between the three main political parties and the 
levels of non-response are considerably higher than for the vote intention question in the same survey. This means that changes in party issue competence ratings reflect substantive variations for each party, rather than just an increase for one party denoting a decrease for another. Furthermore, it is highly improbable that the measure relates to only one issue at any time point, or that the measure relates predominantly to one issue for prolonged periods. ${ }^{4}$

The analysis explores the degree to which trends in vote intentions are responsive to trends in evaluations of issue competence for incumbent and opposition parties, and conversely the degree to which trends in issue competence are responsive to trends in vote intentions. Where individuals change their evaluations, these individuals drive the trends in the macro-level data. If individuals change their evaluations at random, these variations are canceled out through sampling and over time (so long as they are not systematic), so that noise and individual errors are removed (see Erikson et al. 2002: 5, 428429). It is not possible to control for those factors such as individual-level demographics that discriminate between citizens, but the analysis discriminates between macro-level factors that vary over time.

\section{Case selection}

The hypotheses are evaluated in the context of Great Britain between 1971 and 1997. As noted, this country system produces strong party-governance, such that the incumbent in office is drawn entirely from the majority party (except for one notable exception, discussed below). The period between 1971 and 1997 is determined by the availability of data and covers six 'cases' of governing party status, the Conservatives 1971-1974, Labour 1974-1979, the Conservatives 1979-1983, 1983-1987, 1987-1992 and 1992-1997. There are twelve examples of parties in opposition, either the Conservatives or Labour, and the third party, the Liberal Democrats.

One case provides mixed expectations: the period including the 'Lib-Lab pact', which took place between March 1977 and July 1978. During these years, the Liberal Party collaborated with Labour ministers across a range of policy areas, and so it is possible that this period could be conceived as a case of opposition (for the majority of the time) or a case of shared incumbency, unlike the formalised period of coalition government in Britain following the 2010 election, in which the Liberals would be a clear incumbent party, albeit in a shared arrangement. (Note that our data series ends in 1997.)

In all cases, electoral cycles of approximately four years are analysed in turn. These periods enable meaningful inference because they range in length from between 35 and 63 monthly observations. This means we cannot 
disaggregate the 1974-1979 period to isolate the period of the Lib-Lab pact, but the case is given further consideration. The entire period is illustrated in Figure 1 using vote intention for each party, with key political events depicted.

Figure 1 provides a pictorial disaggregation of those cases and parties in which we expect to see the first hypotheses supported for governing parties, and the reverse cases in which we expect to see the second and third hypotheses supported for opposition parties. The series encompasses two changes of the party in government, and so there is a Conservative period in opposition and a Labour period in government. First was the Conservative Heath government - between March 1971 and February 1974. The second were the Labour governments of Wilson and Callaghan between February 1974 and May 1979. The third were the Conservative governments of Thatcher and Major between May 1979 and January 1997.

\section{Data and methods}

\section{Issue competence}

Data about vote intention and the 'best party to handle the most important/ urgent problem' were compiled from the Gallup Political and Economic Index (Gallup Organization 1959-2001). This covers more than 300 continuous months from March 1971 to April 1997, with values generated for 15 missing values by linear interpolation and the average value for five months where there were multiple polls. ${ }^{5}$ The sample size for the data tends to be between 1,000 and 1,200 each month.

Gallup's poll question about the 'most important problem' ('MIP') is the most continuous time series measure of public attention to issues in Britain. From September 1959, Gallup asked: 'Which of these is the most important problem facing the country today?' In March 1965 the wording was changed to: 'Which would you say is the most urgent problem facing the country at the present time?' From March 1971 Gallup started to ask: 'Which party do you think can best handle that problem?'. They discontinued the question in April 1997. The issue competence measure is the percentage ranking of the 'best party to handle the most important problem' for each party.

\section{Vote intention}

Between June 1943 and March 1999 Gallup asked: 'If there were a general election tomorrow, which party would you support?' The reported results also included responses for the follow-up question 'Which party are you most 


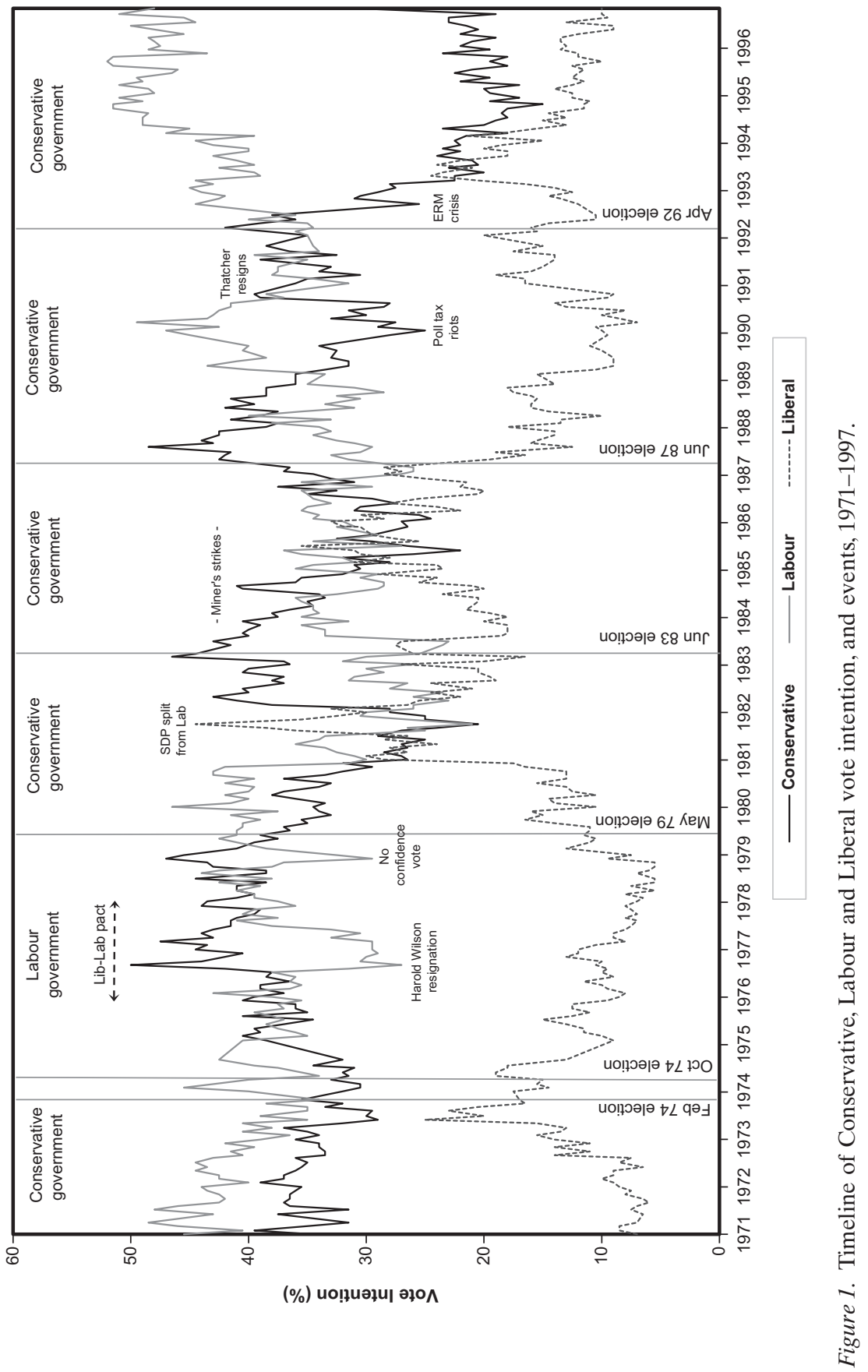


inclined to vote for?' where the initial response had been 'don't know', capturing both strong and weak vote preferences. The vote intention and issue competence series for the Conservatives are plotted in Figure 2.

These series tend to track together over time and share a significant degree of common variance. ${ }^{6}$ Whilst these issue competence and vote intention series might be expected to co-exist in some kind of moving equilibrium, just as vote support and prime ministerial approval exist in an error-correction relationship (see Clarke \& Stewart 1995; Clarke et al.1997, 2000; Clarke \& Lebo 2003), Figure 2 cannot reveal the direction of interaction. This can be achieved by estimating the temporal relationships between the series using tests for Granger-causation. Findings of Granger-causation do not preclude the possibility that a common exogenous process is driving causal relationships in the data, which is measured cross-sectionally at a monthly level.

\section{Method of analysis}

The analysis is formulated to enable measures of competence and vote intention to act as an independent or a dependent effect and the data are allowed to determine the stronger temporal relationship. The measurement of Granger-causation between time series (Granger 1969) considers whether the past values of a variable $x$ improve prediction of another variable $y$ relative to prediction of $y$ from past values of itself alone. ${ }^{7}$ It is said $x$ 'Granger-causes' $y$ if past values of $x$ tend to predict future values of $y$. This does not refer to causation in the strictest sense but, prima facie, to the predictive content of one measure in relation to another (Granger 1988). ${ }^{8}$ The Granger approach is particularly useful because it provides a means for investigating whether past values of the vote intention series provide statistical information about subsequent values of the issue competence series, or vice versa. The contemporaneous relationship between the variables is incorporated through inclusion of the past values of both $x$ and $y$ in determining whether past values of $x$ Granger-cause future values of $y$. While variables might move together over time, the test for Granger-causation provides a means for determining temporal ordering. Determining whether issue competence tends, over time, to lead vote intention is a substantive question. It indicates important underlying dynamics. A standard $f$-test is estimated for each case of incumbent and opposition status to determine whether past values of issue competence affect subsequent values of vote intention, and vice versa. ${ }^{9}$ As an independent variable, lagged vote intention encapsulates the combined effects of prior evaluations over time and the likely effects of party choice upon the formation of issue competence ratings. 


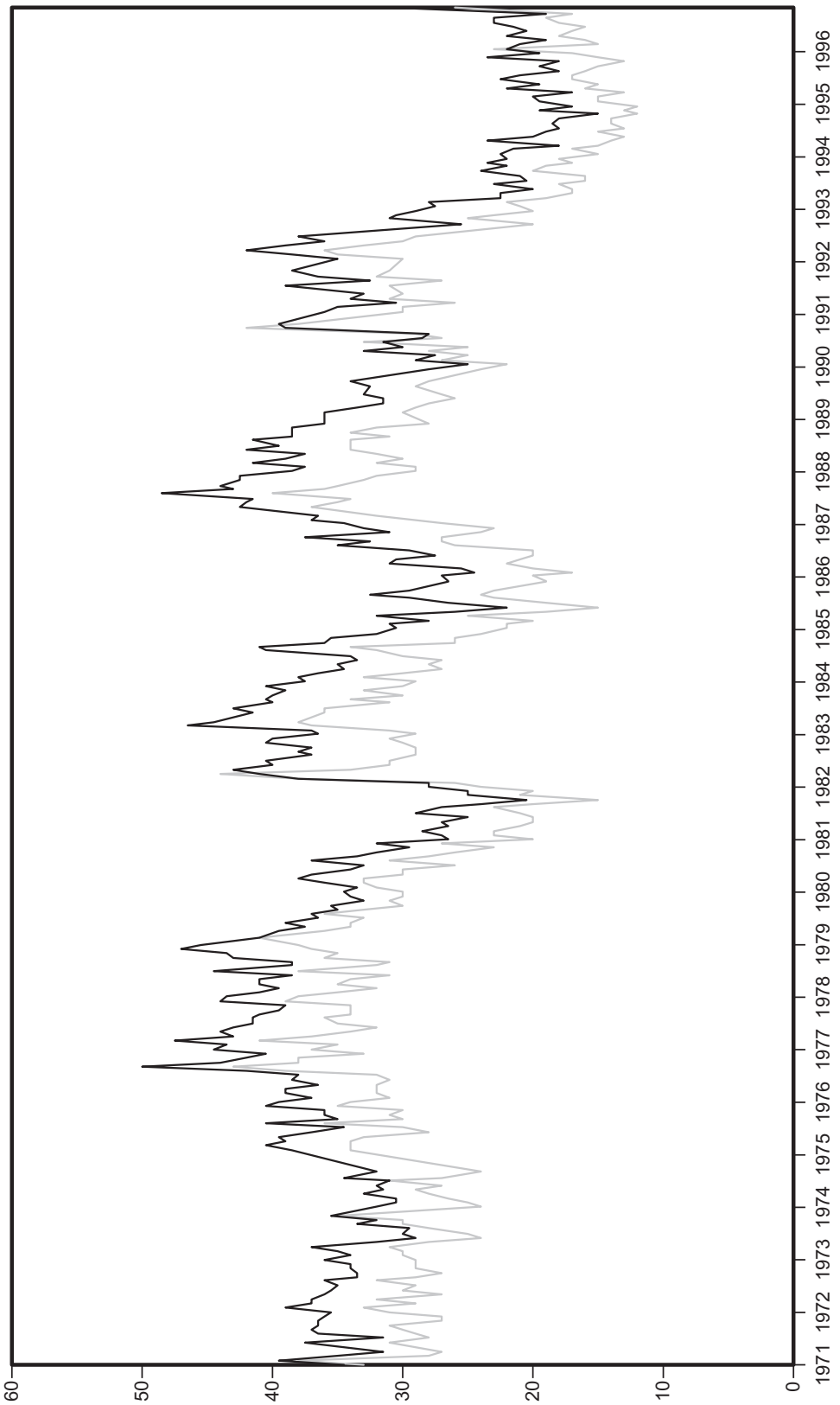

o 
Error-correction models are also used to test the significance and predictive power of the issue competence measure against other commonly used aggregate measures. A period is used in which leader effects, economic voting and government approval have been shown to be important in time series analysis of vote choice and in which these data have been collected: the Thatcher government between May 1979 and November 1990 (Sanders et al. 1987; Sanders 1996, 1999; Clarke \& Stewart 1995; Clarke et al. 1997, 2000). These analyses allow us to establish the predictive content of issue competence net of other commonly used variables - an important step since the issue competence measure had not been collated or analysed to date. The strengths of short- and long-run effects are tested for the issue competence measure against the shortand long-run effects associated with measures of prime ministerial approval, government approval, personal economic expectations, national retrospective economic evaluations and the lagged (error-correcting) effect of vote. This last measure is important if analyses are to parse out any effects of the aggregate performance measures from prior party support, especially since no macropartisanship measure is available for Great Britain at a comparable monthly level. The additional aggregate-level variables are as follows.

\section{Prime ministerial and government approval}

Starting in the late 1930s, Gallup surveyed the public about its satisfaction with performance of the Prime Minister: 'Are you satisfied or dissatisfied with ... as Prime Minister?' offering possible responses of 'Satisfied', 'Dissatisfied' and 'Don't Know'. From the 1940s, it also asked about government performance: 'Do you approve or disapprove of the government's record to date?' ('Approve', 'Disapprove' and 'Don't Know'). The aggregate measures of approval are the percentage of respondents answering 'Satisfied' for prime ministerial performance and 'Approve' for government performance.

\section{Personal economic expectations and national retrospective economic evaluations}

From the 1970s onwards, Gallup regularly asked a series of questions about consumer sentiment. The 'feel-good factor' question, or personal economic expectations (PE), was surveyed from 1974 and asked individuals about expectations for their own household for the upcoming year: 'Do you consider the financial situation of your household in the next 12 months is likely to ...?', with slight variations in question wording over time and possible responses: 'A Lot Better', 'A Little Better', 'Stay The Same', 'A Little Worse', 'A Lot Worse' and 'Don't Know'. Gallup also asked the public about its retrospective 
economic evaluations (NR) concerning the state of the economy in the past year: 'Do you consider that the general economic situation in this country in the last 12 months has...?', with the possible answers: 'Improved a lot', 'Improved slightly', 'Remained the same', 'Deteriorated Slightly', 'Deteriorated a lot' and 'Don't know'. Personal economic expectations and national retrospective economic evaluations are calculated by subtracting the total of negative responses from the total of positive responses on the scale.

\section{National and political events}

We also consider the effect of a selection of important events from past studies of party support in Britain (in particular, Clarke et al. 2000; Clarke \& Lebo 2003). This is composed of separate variables for the Falklands War (May 1982), the miner's strikes (March 1985) and the poll tax riots (March 1990), along with the (temporary) effects of the general elections of 1983 and 1987. We also include a summary variable (replicating Clarke et al. (2000) and Clarke \& Lebo (2003)) that indexes miscellaneous events that occurred between 1979 and 1990, coded ' 1 ' for months in which there was an intervention linked to an increase in support for the Thatcher governments, coded ' -1 ' for months in which there was an intervention linked to a decrease in support, and coded ' 0 ' for other months.

The results are first reported for Granger-causation tests and the errorcorrection model for the incumbent party analysis $(H 1)$, followed by results for analyses pertaining to opposition parties where we offer tests of the second and third hypotheses: that vote intention will lead to issue competence ratings (H3) and that governing party issue competence ratings will lead to opposition party issue competence ratings $(\mathrm{H} 4)$.

\section{Results: Incumbent parties}

Granger-causation tests are estimated for all election cycles specified in Figure 1 for the incumbent parties in each case: Labour and the Conservatives. The Liberal Party is also included as an incumbent party (and later an opposition party) between 1974 and 1979. The estimated $f$-test statistics test whether vote support does not Granger-cause best party and whether best party does not Granger-cause vote intention, such that where the $f$-test is significant there is Granger-causation between the variables. The results of tests for Grangercausation, each at a lag of one month, ${ }^{10}$ between vote intention and competence evaluations, are reported in Table 1. 


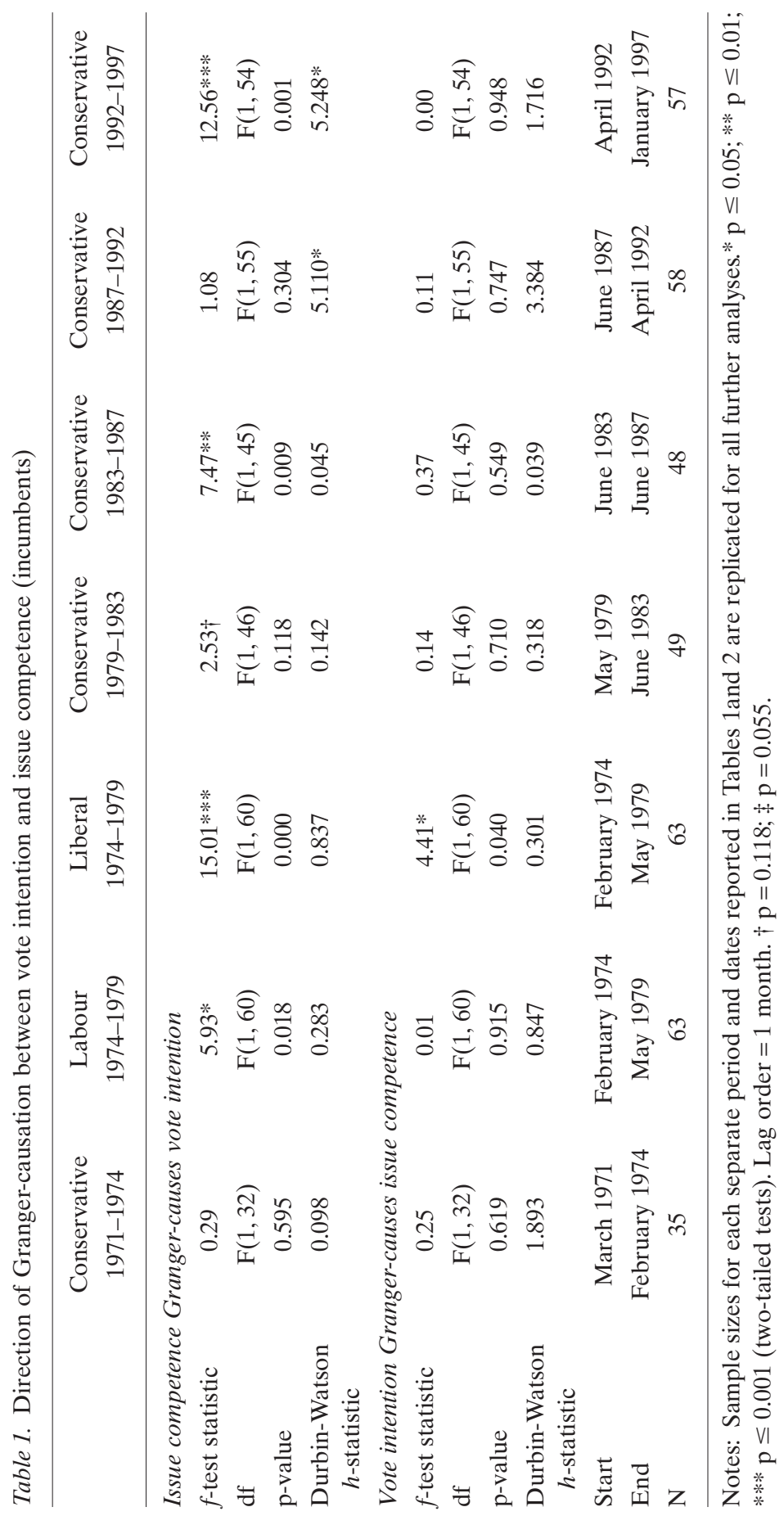


Focusing on the first row of Table 1 , the $f$-test statistics indicate that for five out of the seven election cycles where a party is in government, issue competence evaluations Granger-cause levels of governing party vote intentions. These findings provide important evidence with regard to the temporal ordering of the variables and are consistent with $H 1 .{ }^{11}$ The significant results include the Labour government between 1974 and $1979(f=5.93, \mathrm{p} \leq 0.05)$ and the Liberal opposition for the period $(f=15.01, \mathrm{p} \leq 0.001)$ and so the rewardpunishment issue competence hypothesis is supported for all three parties when in government, suggesting that the relationship may be due to incumbency status rather than being an artifact of party choice.

There is also mixed support for the first hypothesis, however. In two cases where an incumbent party is in situ, there is no Granger-causation between trends in issue competence ratings within the electorate and vote intentions. The exceptions are the Conservative governments between 1971 and 1974, and between 1987 and 1992. Context-driven factors may attenuate the effects of issue competence for some periods, if other predictors become more important (e.g., the state of the economy, or the support for a candidate), as may be intuitive for those periods. However, in most cases, the incumbency model performs as we expect.

Table 1 also provides the results of the tests for Granger-causation from vote intention to issue competence for incumbent parties. A significant $f$-test statistic would signify a statistical finding in refutation - that is, vote intention Granger-causes issue competence, which is a relationship we only expect for opposition parties (H3). Most striking in Table 1 is the lack of any evidence of Granger-causation in this direction in six cases of incumbency. This provides greater confidence in the reward-punishment expectation for incumbents, suggesting that when issue competence has an effect, it is only in the direction of competence to vote, rather than vice versa. The only exception is the Liberal Party between 1974 and 1979. However, this gives support to the incumbencychallenger distinction since in the only case in which we find dual temporal dynamics, it is for a party and within a period in which that party had responsibilities in government.

For the remaining six cases, ratings of vote intention fail to improve upon values of issue competence relative to past values of issue competence on evaluations of competence in the future. The asymmetry in these relationships provides support for the application of Granger tests. If the results were purely an artifact of contemporaneous feedback, where lag information about the two series is not unique, the $f$-test results would be symmetrical where $\mathrm{x}$ Grangercauses $\mathrm{y}$ at the same time as y Granger-causes $\mathrm{x}$.

The tests for Granger-causation in both directions for incumbents give support to the reward-punishment issue competence hypothesis, strengthened 
by the absence of Granger-causation in the opposite direction in these cases. Scrutiny of the issue competence measure is needed to have further confidence in the reward-punishment hypothesis for incumbents.

\section{An error-correction model of incumbent vote including issue competence}

There is an extensive literature on macro-level effects of personal economic expectations (Sanders et al. 1987; Sanders 1996 1999), national retrospective economic evaluations (Clarke \& Stewart 1995; Clarke et al. 2000) and prime ministerial leadership (Clarke \& Stewart 1995; Clarke et al. 1997, 2000; Clarke \& Lebo 2003) on the vote in the British context. This mirrors debate in the United States on the effects of retrospective evaluations (Fiorina 1981) and economic expectations on presidential approval and vote choice (Mackuen et al. 1992; Erikson et al.2002). The measure of issue competence presented in this article must therefore be compared with these alternative predictors, and also with important events from past studies of party support in Britain (in particular, Clarke et al. 2000; Clarke \& Lebo 2003). This has the advantage of validating the results reported in Table 1 before proceeding to further Grangercausation tests for challenger parties, and also of providing additional empirical information about this measure. An error-correction model of vote choice is estimated comparing the effects of issue competence alongside existing aggregate variables. This is necessarily confined to the period of Thatcher government between May 1979 and November 1990, when all variables are available.

The error-correction framework is consistent with evidence that vote intention and issue competence track together over time (as in Figure 2), where a change in one variable exerts a kind of magnetic attraction over the other (e.g., Clarke \& Stewart 1995; Clarke \& Lebo 2003). While error-correction is often considered to be isomorphic with co-integrating processes (Engle \& Granger 1987), as variables drift together over time, this model specification is acceptable for modeling short-run and long-run relationships in the context of stationary as well as non-stationary data (Beck 1991: 70; De Boef \& Keele 2008: 189-190). It also provides a more general framework for analyses of short- and long-run relationships and for diagnosis of dynamic effects.

A single equation error-correction model of issue competence and vote intention, and of other predictors with vote intention, enables comparison of the strength of these relationships across measures. This can be represented in the form:

$$
\Delta \mathrm{Y}_{\mathrm{t}}=\alpha_{0}+\beta_{1} \Delta \mathrm{X}_{\mathrm{t}}+\beta_{2} \mathrm{Y}_{\mathrm{t}-1}+\beta_{3} \mathrm{X}_{\mathrm{t}-1}+\beta_{4} \mathrm{Z}_{\mathrm{t}}+\mu_{\mathrm{t}}
$$

where changes in vote intention $\left(\Delta \mathrm{Y}_{\mathrm{t}}\right)$ are a function of short-run changes $\left(\Delta \mathrm{X}_{\mathrm{t}}\right)$ and the long-run level $\left(\mathrm{X}_{\mathrm{t}-1}\right)$ of the independent variable as well as the 
contemporaneous effect of events $\left(\mathrm{Z}_{\mathrm{t}}\right)$. The lagged value of the dependent variable $\left(\mathrm{Y}_{\mathrm{t}-1}\right)$ measures the rate of re-equilibration $\left(\beta_{2}\right)$ in response to shocks to its long-run equilibrium state. This error-correction parameter captures the rate at which long-term levels of party support move in response to a change in one of the predictor variables - issue competence or prime ministerial approval, for example. The value of the parameter should, by construction, be negative and between 0 and -1 . The closer this value is to -1 , the stronger the rate of correction. This model specification therefore captures both the shortrun and long-run of these variables on party support, and the strength of corrective feedback of party support in response to shocks to its long-term level.

The model is fitted with the Prais-Winsten method to control for serial autocorrelation of the residuals $\left(\mu_{\mathrm{t}}\right)$, estimated as the first-order autoregressive process: $\mu=\rho \mu_{\mathrm{t}-1}+\varepsilon_{\mathrm{t} .}{ }^{12}$ The results of the error-correction models of governing party support are reported in Table 2 . The first five columns estimate the parameters individually, and the last column presents the full model including all indicators. The results for the individual models in Table 2 suggest that issue competence, prime ministerial and government approval, personal economic expectations and national economic evaluations each has a significant effect upon vote intention in both the short and long runs. ${ }^{13}$ Issue competence provides explanatory power in addition to existing commonly used measures.

There are notable differences in the relative strength of short-run and long-run effects, suggesting that issue competence offers important additional information about party support. With respect to short-run effects, changes in governing party vote intention are most sensitive to changes in issue competence $\left(\beta_{1}=0.647, \mathrm{p} \leq 0.001\right)$, followed by government approval, then prime ministerial approval, personal economic expectations, and lastly by national economic retrospective evaluations. An increase of 1 per cent in the issue competence rating is associated with a 0.65 per cent increase in governing party vote intention; a 1 per cent increase in government approval is associated with a 0.47 per cent increase in vote intention, and so on. ${ }^{14}$

Vote intention is also responsive to changes in long-run levels of issue competence, compared to government approval, prime ministerial approval, personal economic expectations and retrospective national economic evaluations. Therefore, vote choice is most responsive to government approval in the long run, whereas issue competence effects tend to be strongest in the short run. ${ }^{15}$ Together these short- and long-run effects highlight the importance of issue competence in a dynamic context where effects are distributed over time, and provide further support for the hypothesised reward-punishment dynamic with respect to issue competence. The error-correction term for the issue 


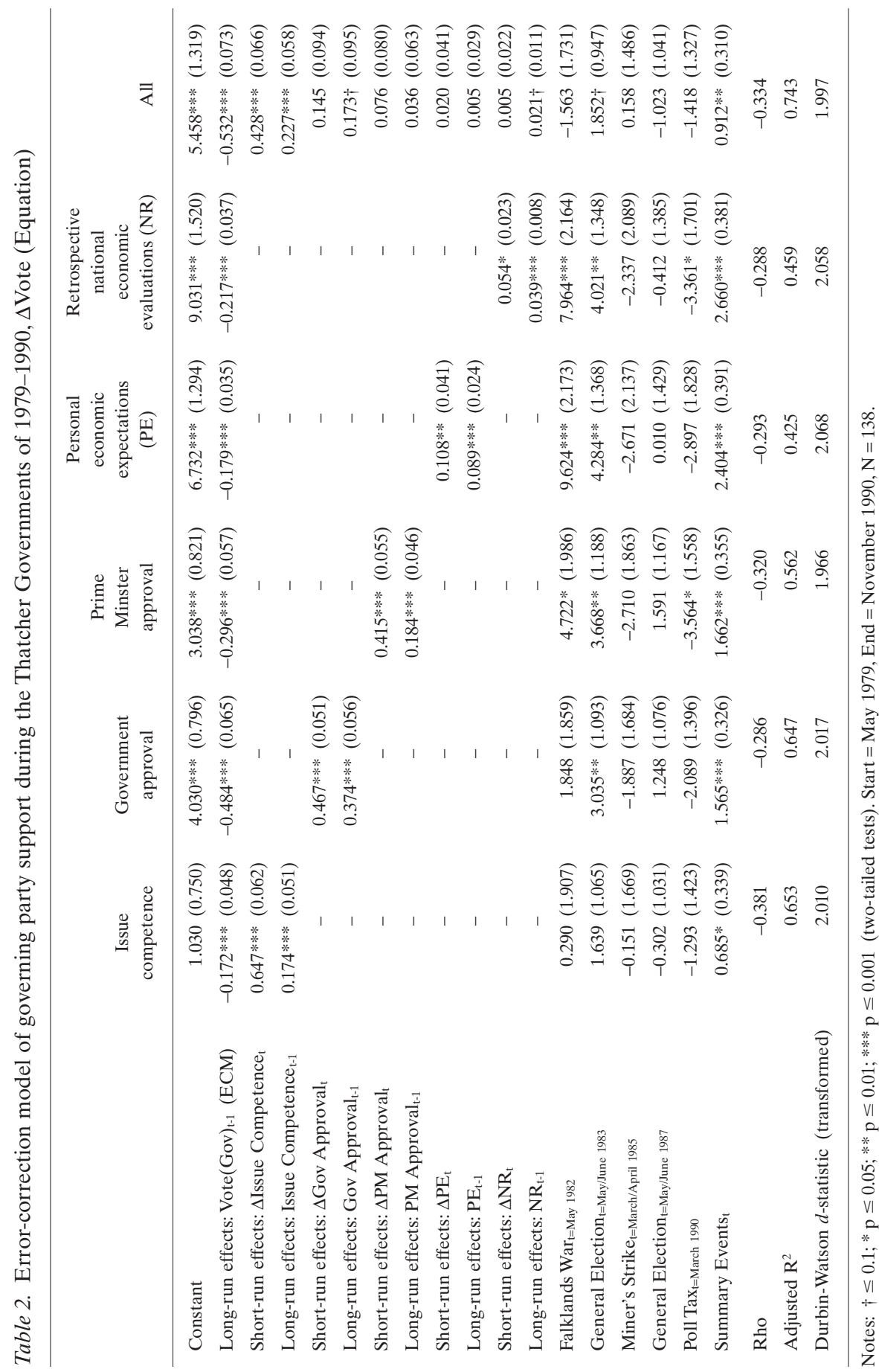


competence model indicates that 83 per cent of the disequilibrating shock remains after one month, 69 per cent after two months, 57 per cent after three months, and so on. In contrast, the rate of correction is quicker for government and prime ministerial approval: short-run changes in issue competence persist some time after similar shocks have worn off on government approval and leadership ratings.

Across the models, the results are broadly consistent with previous expectations regarding the effect of political events on support for the Thatcher governments. Conforming both to theoretical expectations and evidence from previous studies, the summary variable is positive and significant for each of the models. However, none of the other events are found to have significant effects in the models including just issue competence. This suggests that the effects of events are subsumed in variation in the issue competence measures. ${ }^{16}$ The Falklands War and general election of 1983 are found in most cases to have a positive and significant effect on governing party support. The Poll Tax riots have a negative and significant effect in the models that include prime ministerial approval and retrospective national economic evaluations, though the coefficients are broadly consistent across all the models. In the overall model, the relative lack of significant effects of political events can be attributed to the measures of issue competence and government approval capturing some of the variance attributable to events.

In the final column of Table 2 the measure of issue competence is evaluated in a full model. In this model, only issue competence and government approval have significant effects upon vote intention. Furthermore, the short-run and long-run effects of issue competence are each greater than the short-run and long-run effects for government approval. Therefore, the public's evaluation of issue competence and government performance are the most significant predictors of vote choice. The strength of error-correction is superior to any of the individual models, indicating that shocks to the long-run equilibrium are absorbed at a faster rate. ${ }^{17}$ The final model therefore gives strong support to a reward-punishment effect of issue competence judgements for the Thatcher governments between 1979 and 1990.

To test for weak exogeneity of issue competence to vote intention, an error-correction model of issue competence ratings as a function of government and prime ministerial approval (issue competence $=$ approval) was also estimated using residuals from a regression of party support against issue competence ratings, instead of the error-correction component. The residuals were not significant at the 95 per cent level. The models were further re-estimated with the Engle-Granger two-step method in order to test for weak exogeneity, using residuals from a regression of issue competence ratings 
against government or prime ministerial approval (see Table 3). The residuals are not significant at the 95 per cent confidence level for both government and prime ministerial approval.

These analyses lead us to suggest that issue competence ratings provide valid indicators of the impact of competence upon vote intentions - perhaps more valid than other variables. It is possible that leadership effects and subjective evaluations of past and future economic circumstances are incorporated within the dynamic relationship between vote intention, issue competence and government approval, negating otherwise significant effects of economic evaluations variables. This implies that issue competence and government approval ratings contain some information about prime ministerial satisfaction, personal economic expectations and national economic retrospective evaluations. However, their effects appear to be subsumed within the measures of issue competence and government approval. In light of these findings, and the Granger tests for incumbent parties over the 1979-1997 period reported in Table 1, we proceed to evaluate the dynamics between issue competence and vote choice for parties in opposition.

\section{Results: Opposition parties}

Granger-causation tests are now estimated for all election cycles specified in Figure 1 for the three different opposition parties over twelve cases of challenger party status (including again the Liberals between 1974 and 1979), reported in Table 4. The estimated $f$-test statistics consider that vote support does not Granger-cause best party, and that best party does not Granger-cause vote intention. Where this is significant there is Granger-causation between the variables.

The $f$-statistics provide support for the expectations summarised in the second hypothesis (H2) that 'vote intention will not be predicted by issue competence ratings for parties in opposition'. In 10 out of 11 cases of clear opposition, and 10 out of all 12 cases including the period of the Lib-Lab pact, the second hypothesis is supported. In almost every case in which the Conservatives, Labour or the Liberals (or SDP-Liberal Alliance or the Liberal Democrats) were challenging the incumbent, values of issue competence associated with these opposition parties fail to offer better predictors of vote intention for the opposition than past values of vote. These findings are in clear contrast to those in Table 1 for incumbents, whereby a majority of cases revealed issue competence effects upon vote intention. They denote an important distinction to be made in applying the reward-punishment model to parties out of power. These parties, or candidates, are a central feature to every electoral contest, and 


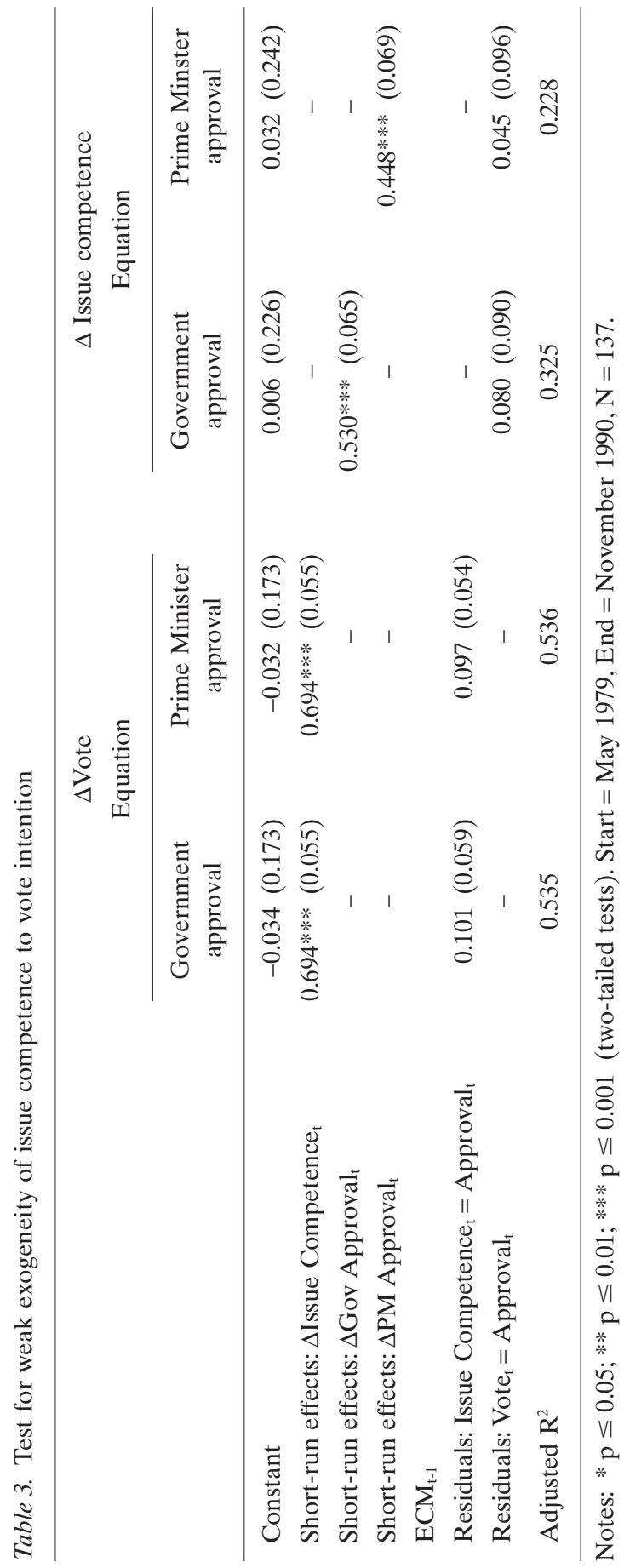




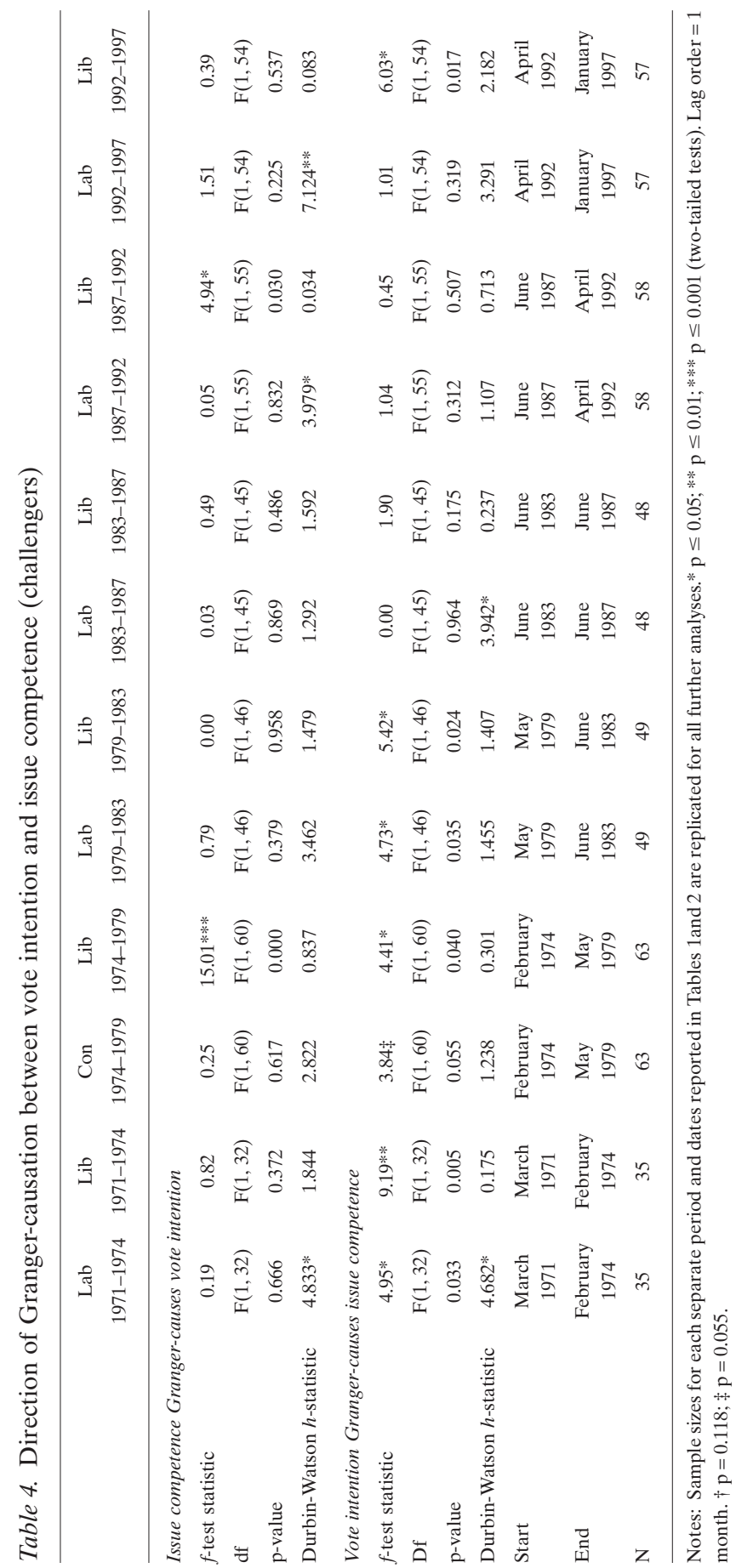


these findings suggest that classic performance models do not apply to these opposition contexts using these measures. This is a substantively important finding.

The only exception is the period of the Liberal Democrats between 1987 and 1992. The results for that period might be attributed to the creation of the party in 1988 through the merger of the Liberal and Social Democratic parties. The SDP was a break-away party from the Labour Party and, as such, may have been rated according to the issue handling of the government, receiving greater attention in this context. However, the overall pattern from the first row of Table 4 is one of minimal issue competence effects, and the results hold in the largest majority of cases.

The second row of Table 4, presenting $f$-tests for Granger-causation from vote intention to issue competence, provides some support for $H 3$, but with exceptions. It was argued above that current values of vote intention may serve as better predictors of issue competence ratings for oppositions since voters have fewer reliable cues and signals on which to judge the opposition. In seven cases out of twelve, the aggregate series lend support to these expectations: vote intentions Granger-cause issue competence ratings. Importantly, this direction of causation was not found in any case of incumbency in Table 1 above. The results for oppositions therefore suggest that oppositions may benefit from improved competence ratings by improving their overall support, whereas a simple reward-punishment effect is more robust for incumbents. This finding has an important implication theoretically, since it suggests that issue competence ratings are not static and fixed, but responsive to fluctuations in party support. However, Table 4 also highlights a period in which these findings, and findings for issue competence effects on vote, are found to show no Granger-causation in either direction: the 14-year period of Labour opposition between 1983 and $1997 .{ }^{18}$ Therefore, although there is support for the 'opposition party hypothesis' (in cases covering a 12-year period and three different parties in opposition), the period of Labour opposition under the Thatcher and then the Major governments of the 1980s and 1990s does not support this hypothesis.

For this period it may be particularly relevant to consider the role of the incumbent in generating competence ratings of the opposition, summarised in H4. In the period shown in Table 4, in which there are no statistically significant tests of Granger-causation from competence to vote intention, or vote intention to competence, the Labour Party had been in opposition for a long time, and the incumbent was very strong. Before this period, there was greater alternation of government, as shown in Figure 1. During the Conservative administration, perceived policy failings may have translated positively to Labour's issue competence ratings, supporting the 'incumbent-opposition hypothesis $(\mathrm{H} 4)$ '. 
The final stage of analysis proceeds to test the fourth hypothesis, using current values of incumbent issue competence to evaluate whether these trends predict future values of challenger party issue competence. Table 5 presents results for Granger-causation tests between the issue competence ratings of the governing party upon those of the opposition. The table reveals evidence of Granger-causation from governing party issue competence ratings to opposition party issue competence for the time period between 1983 and 1997 - the period in which vote intention did not Granger-cause issue competence ratings for opposition parties. ${ }^{19}$ These findings give support to the 'incumbent-challenger hypothesis'. Conservative incumbent issue ratings improve predictions of Labour Party issue competence ratings relative to past values, and these findings hold where vote intention does not Granger-cause issue competence. ${ }^{20}$ These findings, in a period in which vote intention does not Granger-cause issue competence, would be consistent with the interpretation that public ratings of party competence are driven by governing party competence when the party has been out of power for some time. Prior party support is no longer a useful heuristic. These findings would also be consistent with an interpretation based upon the strength of fluctuations in competence cues provided by the Thatcher government.

The absence of clear competence effects upon vote choices and the effects of both vote intention and governing party competence on opposition party competence ratings reveals an important asymmetry that has important consequences. It could be argued that a trade-off between evaluations of governing and opposition party is to be expected, by data construction, where a decrease in the competence rating of one is matched by an increase in the other. Our analyses suggest that it is not necessarily the case that if the public, in the aggregate, increase their rating of one party as the party best able to handle the most important problem then this must be at the expense of a decline in the ratings of the second party. First, these relationships are not found in all cases of opposition party status, which we would expect if the findings were purely a product of data construction. Second, the number of 'undecided' or 'don't know' responses for issue competence is 12 per cent higher, on average, than for vote intention, and bivariate regressions of the effect of party support for both Labour and the Conservatives (but not the Liberals) on 'undecided' and 'don't know' responses for issue competence are significant and negative. This indicates that when each of the major parties suffers a decline in support, there follows an increase in undecided respondents, rather than simply a data driven transfer of positive ratings from one party to another.

It is interesting that two different explanations of incumbent competence ratings emerge: either competence ratings for opposition parties are 


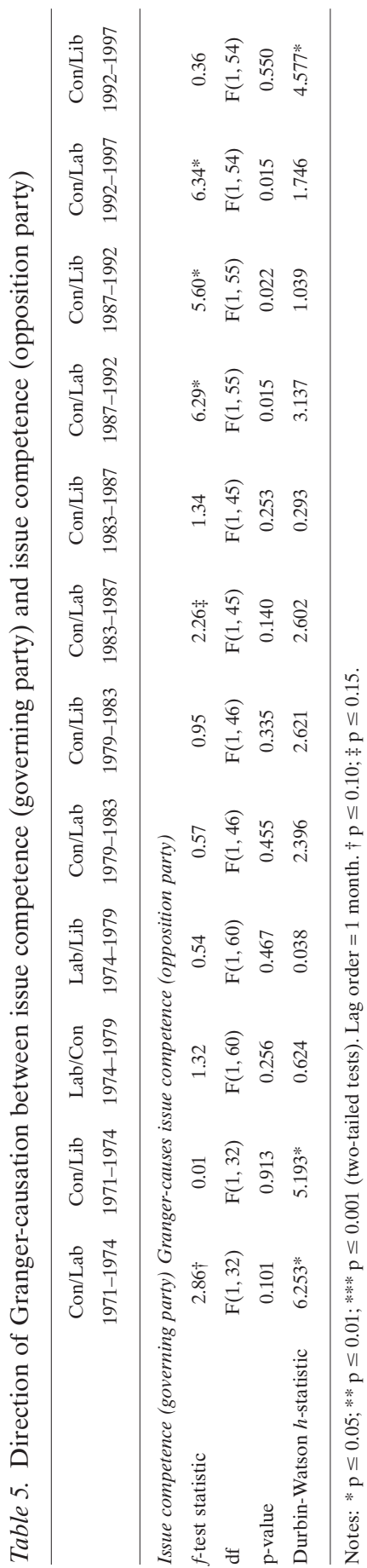


Granger-caused by prior values of vote, or they are Granger-caused by the competence ratings of the incumbent. However, for no case in the entire period do issue competence ratings Granger-cause vote choice for parties in opposition. There is greater and clearer support for the absence of the rewardpunishment model for challengers and the presence of this model for the incumbent. Furthermore, the fact that the 'opposition party hypothesis' appears to hold in the earlier time points, but the 'incumbent-challenger hypothesis' tends to hold for the later time points, suggests that further work is needed to understand the causal factors in these respects. It is plausible that existing party support serves as a generator of changes in issue competence for opposition parties when there is regular alternation of government. However, when an incumbent is in power for a longer period, that party's issue competence ratings offer the most reliable determinants of issue competence ratings for the challenger.

Two clear conclusions can be drawn. Where the reward-punishment model of issue competence on electoral results is applied, it is applicable to parties in power but not to parties out of power. While intuitive, this observation has important implications. Furthermore, if we are to understand the nature of issue competence ratings for parties in opposition, we should either look to the dynamics of party support as a driver of issue competence, or to the issue competence ratings of the incumbent.

\section{Conclusions}

Real world elections generally appear to be highly asymmetric: incumbents are significantly more likely to stay incumbents than are challengers to become incumbents. (Fiorina 1977: 620)

When scholars consider the electoral effects of 'valence issues' (Stokes 1963) those issues upon which voters judge and make their choice on the basis of a party's competence - they should expect to find systematic differences for governing and opposition parties. Voters attribute reward and punishment for issue handling or performance to the incumbent party, but cannot rely on such information when forming evaluations of the opposition. This article has examined the time series inter-relationships between issue competence ratings and vote intentions over a 26-year period in Britain, for governing and opposition parties. The results reveal that voters' ratings of opposition party issue competence are led by prior vote intention, or by the issue competence ratings of the government, suggesting that voters rely on existing cues, or the stronger relative performance cues of the government. The analyses also revealed a 
statistically and substantively important effect of issue competence ratings for governing parties upon vote intention, in the first time series analysis of this aggregate-level variable. Issue valence is an important explanatory variable, but governing and opposition party context is also very important.

The implications of these findings are threefold. These findings have useful analytic implications. When scholars model the effects of valence in vote choice models, they might consider that issue competence variables are substantively and statistically meaningful. Just as Clarke et al. $(2004,2009)$ have analysed issue competence in their analysis of British electoral data, so scholars in other countries may benefit from incorporating measures of issue valence. Our measure will enable longitudinal issue competence to be incorporated into existing aggregate level analysis in Britain (e.g., Sanders et al. 1987; Sanders 1996, 1999; Clarke \& Stewart 1995; Clarke et al. 1997, 2000; Clarke \& Lebo 2003; Lebo \& Young 2009), and similar measures should be sought in different countries. Our analyses suggest that using proxies for competence, such as economic ratings or leader ratings, may overlook the importance of citizens' evaluations of parties on policy competence. Scholars may also note that apparent issue competence effects for opposition party vote choice may indicate indirect governing party competence ratings, or an endogenous relationship. Controlling for prior vote choice or party identification, as well as government handling of issues, will avoid the reporting of spurious relationships. We might also expect other variables to be more strongly associated with vote choice for the opposition party, as suggested by Butt (2006).

Furthermore, our findings may have implications for forecasting models, alongside established variables such as economic performance (Lewis-Beck \& Stegmaier 2000) and prime ministerial approval (Lebo \& Norpoth 2007). We would expect issue competence ratings to provide very useful information for predicting vote support for the government, but less reliable information for predicting the vote support of the opposition. Future directions might also consider the predictive power of issue competence compared to vote intention polls over the timeline of the electoral cycle (Wlezien \& Erikson 2002).

The findings have implications for party strategies and party competition theories. Work by Petrocik (1996; Petrocik et al. 2003) proposes that opposition parties can gain 'ownership' or positive competence ratings and associations when the incumbent suffers reputational crises. Therefore opposition parties should capitalise on government performance failures, but may otherwise struggle to gain a positive competence rating through their own efforts. Our findings suggest that governing parties will benefit or suffer from competence improvements or declines, but opposition parties' competence ratings may be influenced by their broad popularity, or by the performance of the government. We would therefore expect governing parties to emphasise issue 
handling in their strategies when they have positive ratings, but opposition parties to direct voters to other electoral advantages.

In future, scholars may further explore the contexts in which opposition parties' competence ratings are driven by those of the incumbent, and when prior party support is a more powerful heuristic. However, on the basis of the current findings, the normative implications are encouraging. Insofar as electoral incentives motivate parties to govern well (see Kiewiet 2000), our findings suggest that voters use performance information to formulate their vote choices when it most matters - when these are directed towards the party in power. The conclusions therefore give valence-related support to the responsible party model (see Jones \& McDermott 2004).

Finally, the findings have implications for understanding and predicting the potential electoral consequences of recent events in British politics, whereby a formal coalition was struck between the Conservative Party and the British Liberal Democrats. Our data spanned a 26-year time period, allowing us to analyse the time series inter-relationships between issue competence ratings and vote intention for the last previous instance of shared government (albeit in a less formal arrangement) in the Lib-Lab pact between March 1977 and July 1978. The results for this period revealed Granger-causation from vote intention to issue competence for the Liberals, but a stronger statistical relationship from issue competence to vote intention. When this traditional opposition party took responsibility for policy in government, and even when this period was relatively short-lived, there is evidence of a reward-punishment effect of issue competence upon vote choice, shared also by the incumbent Labour Party. Our findings suggest that where responsibility for policy handling is shared by two parties in coalition, and in both instances the Liberals are a 'junior partner', this third party in British politics can expect to be punished at the ballot box for any perceptions of policy failure in government. Furthermore, our results suggest that these effects will not be attenuated for the current Conservative Party leading the coalition arrangement. These findings might also be extended to countries in which proportional systems deliver regular coalition arrangements.

The analysis of valence issues and their effects have risen in prominence in electoral analysis relatively recently (see Clarke et al. 2004, 2009; Bellucci 2006; Green-Pedersen 2007; Belangér \& Meguid 2008; Green \& Hobolt 2008). Our theories and models have been dominated by spatial models (Downs 1957), and by analysis of competence effects via leader ratings, economic ratings and the concept of party identification. Our study adds further support to the relevance of studying issue competence and its relationship to vote, and suggests that in so doing we should take governing party and opposition party status firmly into account. 


\section{Acknowledgements}

The authors wish to thank David Sanders for supplying additional data, and to thank Tarley Smith, Corin-Briault Hutter and Wasel bin Shadat for research assistance. We also wish to thank Scott Matthews, Sara Hobolt, Luke Keele and the Editors and anonymous reviewers at the European Journal of Political Research, for their comments on earlier versions of this article.

\section{Notes}

1. For classic studies, see Campbell et al. (1960); Converse (1964); Miller (1991).

2. It is not possible, for the purposes of our analysis, to analyse the effects of party identification. Therefore, vote intention is used here to represent prior partisan disposition. Party identification data are only available in Britain at the quarterly level, and our issue competence data, and time scales necessary for meaningful contextual analysis, occur at a monthly level, meaning that vote intention is the better choice.

3. With this measure it is not possible to measure the degree to which parties - in government or otherwise - have certain issues on which they are evaluated as more or less competent. The 'best party to handle' question allows for Most Important Problem (MIP) responses to vary across individuals. MIP responses are often quite consistent over time (see Wlezien 2005: 576) and so the question does not reflect short-term fluctuations in problem status despite heterogeneity at the individual level.

4. The data source for these assertions is the analysis of Gallup's 'most urgent/important problem' question, published in its Political and Economic Index between December 1959 and May 2001, available for a comprehensive range of issues, measured most commonly at monthly intervals (see Gallup Organization 1959-2001).

5. If the 'best party' value is generated for missing values through linear interpolation, this is also generated for vote intention (even if this is available), in order that these remain consistent.

6. The series track each other similarly for the Labour and Liberal series.

7. See Freeman's (1983) review of applications of Granger-causation in political science.

8. This assumption is based on the view that cause must precede effect. Granger-causation does not consider the contemporaneous relationship between variables. It is not possible, for example, to determine the direction of instantaneous causation (see Granger $1969,1980)$ since if knowledge of $x$ enables prediction of $y$, then knowledge of $y$ must also enable prediction of $x$. Granger (1969: 430) notes that infrequent observation of $x$ and $y$ can generate spurious inferences of instantaneous causation. Since the Gallup data on issue competence and vote intention is the aggregate of fieldwork conducted over an average of 5.75 days, it is conceivable that any observed contemporaneous interactions might be spurious.

9. The general form of the model for the dependent variable $\mathrm{Y}_{\mathrm{t}}$ at $k$ lags considers that the null hypothesis that the inclusion of additional lags of $\mathrm{X}_{\mathrm{t}-\mathrm{k}}$ in addition to lags of $\mathrm{Y}_{\mathrm{t}-\mathrm{k}}$, does not explain additional variance:

$$
\begin{aligned}
& \mathrm{Y}_{\mathrm{t}}=\beta_{0}+\beta_{1} \mathrm{Y}_{\mathrm{t}-1}+\ldots \beta_{\mathrm{k}} \mathrm{Y}_{\mathrm{t}-\mathrm{k}}+\varepsilon_{\mathrm{t}} \\
& \mathrm{Y}_{\mathrm{t}}=\beta_{0}+\beta_{1} \mathrm{Y}_{\mathrm{t}-1}+\ldots \beta_{\mathrm{k}} \mathrm{Y}_{\mathrm{t}-\mathrm{k}}+\gamma_{1} \mathrm{X}_{\mathrm{t}-1}+\ldots \gamma_{\mathrm{k}} \mathrm{X}_{\mathrm{t}-\mathrm{k}}+\varepsilon_{\mathrm{t}}
\end{aligned}
$$


10. The tests use a lag of one month in all models so that the same expectations can be compared across cases. However, Granger-causation tests are also estimated using vector autoregressive models with lag lengths determined by maximum likelihood (AIC) criteria, and the results are consistent.

11. Diagnostic tests for residual autocorrelation at the first lag, using the Durbin-Watson $h$-statistic here because it is appropriate in the presence of a lagged dependent variable and in the absence of strict exogeneity, generate acceptable values in all instances with just a single exception. That is the non-significant finding for the Conservatives in government between 1987 and 1992 and, therefore, does not affect our substantive inferences.

12. All models were also estimated using the Engle-Granger two-step method which produced similar, if not identical, results. The direction of coefficients and levels of significance were consistent across the one-step and two-step methods. The size and direction of coefficients were also consistent with models of fractional co-integration estimated using the three-step method (see Clarke \& Lebo 2003; Lebo \& Norpoth 2007; Lebo \& Young 2009). The degree of fractional integration of the parent series, estimated with the Robinson (1995) multivariate semiparametric method, are higher than is the series of residuals for the co-integrating regression, consistent with the presence of fractional co-integration (Clarke \& Lebo 2003; Lebo \& Norpoth 2007). The models estimated using the three-step method also provide slightly superior results for serial autocorrelation. Our analyses present the results for the one-step method for clarity of presentation, which enables us to focus on short- and long-run effects. It is possible for over-differencing to introduce a moving average into the estimates, but such an approach is not problematic if the appropriate diagnostics are completed (Plosser \& Schwert 1977). The diagnostics and robustness checks presented indicate that use of the one-step method does not present a threat to inference, while use of the alternative two- or three-step error-correction method does not alter the substance of our inferences.

13. We also test the short- and long-run effects of several objective economic indicators both in individual models and within the full model: the Conference Board leading and co-incident economic indicators and the economic misery index (equal to the rate of inflation plus the rate of unemployment). The short-run effects of coincident economic indicators are found to be positive and significant at the 95 per cent confidence level and the long-run effects of leading economic indicators are positive and significant at the 95 per cent confidence level, while the effects of the economic misery index are not significant in either the short or long runs. The goodness-of-fit of the models is, however, inferior to those that include personal economic expectations and national economic retrospective evaluations.

14. The transformed Durbin-Watson $d$-statistic for each of the models does not indicate the presence of serial autocorrelation, with the value approaching two in each case (where the value is substantially less than two this indicates that successive error terms are positively correlated and where this is substantially more than two the error terms are negatively correlated).

15. The rate of error-correction for issue competence $\left(\beta_{2}=-0.17, \mathrm{p} \leq 0.001\right)$ is significant but not as strong as that for government approval $\left(\beta_{2}=-0.48, \mathrm{p} \leq 0.001\right)$ and prime ministerial approval $\left(\beta_{2}=-0.30, \mathrm{p} \leq 0.001\right)$, but far closer to personal economic expectations $\left(\beta_{2}=-0.18, \mathrm{p} \leq 0.001\right)$ and retrospective national economic evaluations $\left(\beta_{2}=\right.$ $-0.22, \mathrm{p} \leq 0.001)$. As such, a shock to the long-run equilibrium between vote intention 
and issue competence is corrected at a rate of 17 per cent, so that a one-unit deviation in the previous month results in a 0.17 -unit decrease in vote intention in the current month.

16. This is confirmed when an error-correction model, fitted with the Prais-Winsten method, is estimated for issue competence, finding that each of these events have effects on the measure (controlling for the long-run level of issue competence) that are significant and consistent with their effect on party support when other measures are included in the model.

17. The goodness-of-fit of the full model (Adjusted $\mathrm{R}^{2}=0.743$ ) outperforms each of the models that consist of individual vote predictors. The Durbin-Watson $d$-statistic for serial autocorrelation generates acceptable values for each model, with the value approaching two in each case.

18. Diagnostic tests for residual autocorrelation at the first lag generate acceptable values in most instances, with one notable exception where the Durbin-Watson $h$-statistic is significant where there is evidence of Granger-causation: Labour in opposition between 1971 and 1974. The serial autocorrelation present for other non-significant results are removed if an additional lag is included in the Granger-causation test. There must therefore be caution with the conclusions drawn from Table 4 insofar as they apply to these results.

19. The Durbin-Watson $h$-statistic for residual autocorrelation at the first lag generates acceptable values in most instances, with one notable exception where this is significant when there is evidence of Granger-causation - again, Labour in opposition between 1971 and 1974.

20. Bivariate regressions of the effect of lagged incumbent competence on current opposition competence, controlling for effects of lagged opposition competence, confirm that the effect is negative for Labour ratings during the 1983-1987, 1987-1992 and 1992-1997 periods, consistent with the incumbent-challenger hypothesis. Interestingly, the effect is positive for Liberals in the 1987-1992 period and for Labour in the 1971-1974 period. This therefore demonstrates that two of the three parties are together able to improve their competence ratings at the expense of the third (or from decreases in the number of 'don't know' responses, which is higher on average than for vote choice questions). The decline in competence ratings of the Liberals in the early 1970s might be responsible for the positive relationship between the issue competence of Labour and the Conservatives during that short period. Likewise, the political fortunes of the Conservatives and SDP/Liberal Alliance were both in decline during the period 1987-1992, so it is plausible that their competence ratings moved together during this period.

\section{References}

Anderson, C.J. (1995). Blaming the government: Citizens and the economy in five European democracies. Armonk, NY: Sharpe.

Anderson, C.J., Mendes, S.M. \& Tverdova, Y.V. (2004). Endogenous economic voting: Evidence from the 1997 British election. Electoral Studies 23(4): 683-708.

Beck, N. (1991). Comparing dynamic specifications: The case of presidential approval. Political Analysis 3(1): 51-87.

Belangér, E. \& Meguid, B.M. (2008). Issue salience, issue ownership and issue-based vote choice. Electoral Studies 27(3): 477-491. 
Bellucci, P. (2006). Tracing the cognitive and effective roots of 'party competence': Italy and Britain, 2001. Electoral Studies 25: 548-569.

Budge, I. (1987). The internal analysis of election programmes. In I. Budge, D. Hearl \& D. Robertson (eds), Ideology, strategy and party change: Spatial analysis of post-war election programmes in 19 democracies. Cambridge: Cambridge University Press.

Budge, I. \& Farlie, D. (1983). Explaining and predicting elections: Issue effects and party strategies in twenty-three democracies. London: Allen \& Unwin.

Butt, S. (2006). How voters evaluate economic competence: A comparison between parties in and out of power. Political Studies 54(4): 743-766.

Campbell, A. et al. (1960). The American voter. New York: Wiley \& Sons.

Clarke, H.D. \& Lebo, M. (2003). Fractional (co)integration and governing party support in Britain. British Journal of Political Science 33: 283-301.

Clarke, H.D. \& Stewart, M.C. (1995). Economic evaluations, prime ministerial approval and governing party support: Rival models reconsidered. British Journal of Political Science 25(2): 145-170.

Clarke, H.D., Ho, K. \& Stewart, M.C. (2000). Major's lesser (not minor) effects: Prime minister approval and governing party support in Britain since 1979. Electoral Studies 19: 255-273.

Clarke, H.D., Stewart, M.C. \& Whiteley, P. (1997). Tory trends: Party identification and the dynamics of Conservative support since 1992. British Journal of Political Science 26(2): 299-318.

Clarke, H.D., Stewart, M.C. \& Whiteley, P.F. (2004). Political choice in Britain. Oxford: Oxford University Press.

Clarke, H.D., Stewart, M.C. \& Whiteley, P.F. (2009). Performance politics and the British voter. New York: Cambridge University Press.

Conover, P., Feldman, S. \& Knight, K. (1986). Judging inflation and unemployment: The origins of retrospective evaluations. Journal of Politics 48(3): 565-588.

Converse, P. (1964). The nature of belief systems in mass publics. In D.E. Apter (ed.), Ideology and discontent. London, Ont.: Macmillan.

De Boef, S. \& Keele, L. (2008). Taking time seriously. American Journal of Political Science 52(1): 184-200.

Downs, A. (1957). An economic theory of democracy. New York: Harper \& Row.

Enelow, J.M. \& Hinich, M.J. (1981). A new approach to voter uncertainty in the Downsian spatial model. American Journal of Political Science 25(3): 483-493.

Engle, R.F. \& Granger, C.W.J. (1987). Co-integration and error correction: Representation, estimation and testing. Econometrica 55(2): 251-276.

Erikson, R.S., MacKuen, M.B. \& Stimson, J.A. (2002). The macro polity. Cambridge: Cambridge University Press.

Evans, G. \& Andersen, R. (2006). The political conditioning of economic perceptions. Journal of Politics 68(1): 194-207.

Fiorina, M.P. (1977). An outline for a model of party choice. American Journal of Political Science 21(3): 601-625.

Fiorina, M.P. (1981). Retrospective voting in American national elections. New Haven, CT: Yale University Press.

Freeman, J.R. (1983). Granger causality and the times series analysis of political relationships. American Journal of Political Science 27(2): 327-358.

Gallup Organization (1959-2001). Gallup political and economic index. London: Gallup. 
Granger, C.W.J. (1969). Investigating Causal Relations by Econometric Models and Cross Spectral Methods. Econometrics 37(May): 424-438.

Granger, C.W.J. (1980). Testing for causality: A personal viewpoint. Journal of Economic Dynamics and Control 2: 329-352.

Granger, C.W.J. (1988). Some recent developments in a concept of causality. Journal of Econometrics 39(1): 199-211.

Green, J. (2007). When voters and parties agree: Valence issues and party competition. Political Studies 55(3): 629-655.

Green, J. \& Hobolt, S.B. (2008). Owning the issue agenda: Party strategies and vote choices in British elections. Electoral Studies 27(3): 460-476.

Green-Pedersen, C. (2007). The growing importance of issue competition: The changing nature of party competition in Western Europe. Political Studies 55(3): 607-628.

Iyengar, S. \& Kinder, D.R. (1987). News that matters: Television and American opinion. Chicago, IL: University of Chicago Press.

Jacobs, L.R. \& Shapiro, R.Y. (1994). Issues, candidate image and priming. American Political Science Review 88(3): 527-540.

Jones, D.R. \& McDermott, M.L. (2004). The responsible party government model in House and Senate elections. American Journal of Political Science 48(1): 1-12.

Kiewiet, R. (2000). Economic retrospective voting and incentives for policymaking. Electoral Studies 19: 427-444.

Lebo, M. \& Norpoth, H. (2007). The PM and the pendulum: Dynamic forecasting of British elections. British Journal of Political Science 37(1): 71-87.

Lebo, M. \& Young, E. (2009). The comparative dynamics of party support in Great Britain: Conservatives, Labour and the Liberal Democrats. Journal of Elections, Public Opinion \& Parties 19(1): 73-103.

Lewis-Beck, M.S. \& Stegmaier, M. (2000). Economic determinants of electoral outcomes. Annual Review of Political Science 3: 183-219.

Lijphart, A. (1984). Democracies: Patterns of majoritarian and consensus government. New Haven, CT: Yale University Press.

Lodge, M. \& Hamill, R. (1986). A partisan schema for political information processing. American Political Science Review 80(2): 505-520.

MacKuen, M.B., Erikson, R.S. \& Stimson, J.A. (1992). Peasants or bankers? The American electorate and the US economy. American Political Science Review 86: 597-611.

Miller, W. (1991). Party identification, realignment and party voting: Back to the basics. American Political Science Review 82(2): 557-568.

Miller, A.H. \& Wattenberg, M.P. (1985). Throwing the rascals out: Policy and performance evaluations of presidential candidates, 1952-1980. American Political Science Review 79(2): 359-372.

Petrocik, J.R. (1996). Issue ownership in presidential elections, with a 1980 case study. American Journal of Political Science 40(3): 825-850.

Petrocik, J.R., Benoit, W.L. \& Hansen, G.J. (2003). Issue ownership and presidential campaigning, 1952-2000. Political Science Quarterly 118(4): 599-626.

Plosser, C.I. \& Schwert, G.W. (1977). Estimation of a non-invertible moving average process: The case of overdifferencing. Journal of Econometrics 6: 199-224.

Powell, B. \& Whitten, G.D. (1993). A cross-national analysis of economic voting: Taking account of the political context. American Journal of Political Science 37(2): 391414.

Riker, W.H. (1993). Agenda formation. Ann Arbor, MI: University of Michigan Press. 
Robinson, P.M. (1995). Log-periodogram regression of time series with long range dependence. Annals of Statistics 23(3): 1048-1072.

Sanders, D. (1996). Economic performance, management competence and the outcome of the next general election. Political Studies 44(2): 203-231.

Sanders, D. (1999). Conservative incompetence, Labour responsibility and the feelgood factor: Why the economy failed to save the Conservatives in 1997. Electoral Studies 18: 251-270.

Sanders, D. et al. (1987). Government popularity and the Falklands War: A reassessment. British Journal of Political Science 17(3): 281-313.

Sniderman, P., Brody, R. \& Tetlock, P. (1991). Reasoning and choice: Explorations in political psychology. Cambridge: Cambridge University Press.

Stokes, D. (1963). Spatial models and party competition. American Political Science Review 57(2): 368-377.

Van der Eijk, C. et al. (2006). Rethinking the dependent variable in voting behaviour: On the measurement and analysis of electoral utilities. Electoral Studies 25(3): 424-447.

Vavreck, L. (2009). The message matters: The economy and presidential campaigns. Princeton, NJ: Princeton University Press.

Wilcox, N.T. \& Wlezien, C. (1996). The contamination of responses to survey items: Economic perceptions and political judgments. Political Analysis 5: 181-213.

Wlezien, C. (2005). On the salience of political issues: The problem with 'most important problem'. Electoral Studies 24(4): 555-579.

Wlezien, C. \& Erikson, R.S. (2002). The timeline of presidential election campaigns. Journal of Politics 64: 969-993.

Wlezien, C., Franklin, M. \& Twiggs, D. (1997). Economic perceptions and vote choice: Disentangling the endogeneity. Political Behavior 19(1): 7-17.

Address for correspondence: Jane Green, School of Social Sciences, University of Manchester, Oxford Road, Manchester, M13 9PL, UK. E-mail: jane.green@manchester.ac.uk 